\title{
Relationship between Bone Mineral Density Changes and Fracture Risk Reduction in Patients Treated with Strontium Ranelate
}

\author{
Olivier Bruyere, Christian Roux, Johann Detilleux, Daniel O. Slosman, Tim D. Spector, \\ Patrice Fardellone, Kim Brixen, Jean-Pierre Devogelaer, Manuel Diaz-Curiel, Carlina Albanese, \\ Jean-Marc Kaufman, Stig Pors-Nielsen, and Jean-Yves Reginster
}

\begin{abstract}
World Health Organization Collaborating Center for Public Health Aspect of Osteoarticular Disorders (O.B., J.D., J.-Y.R.), University of Liège, B-4000 Liège, Belgium; Department of Rheumatology (C.R.), University of Paris, Hôpital Cochin, 75014 Paris, France; Clinique Générale Beaulieu (D.O.S.), CH-1206 Genève, Switzerland; Department of Rheumatology (T.D.S.), St. Thomas Hospital, London SE1 7EH, United Kingdom; Service de Rhumatologie (P.F.), Hôpital Nord, 80080 Amiens, France; Odense University Hospital (K.B.), DK-5000 Odense, Denmark; Université Catholique de Louvain (J.-P.D.), SaintLuc University Hospital, B-1348 Brussels, Belgium; Fundacion Jimenez Diaz (M.D.-C.), Servicio de Medicina Interna, Unidad de Metabolismo Oseo, 28029 Madrid, Spain; University of Rome La Sapienza (C.A.), 00185 Roma, Italy; Gent University Hospital (J.-M.K.), B-9000 Gent, Belgium; and Department of Clinical Physiology (S.P.-N.), Hillerod Hospital, DK-3400 Hillerod, Denmark
\end{abstract}

\begin{abstract}
Objective: Our objective was to analyze the relationship between bone mineral density (BMD) changes and fracture incidence during 3 -yr treatment with strontium ranelate.
\end{abstract}

Patients: Women from the strontium ranelate arm of the Spinal Osteoporosis Therapeutic Intervention study and the TReatment Of Peripheral OSteoporosis study were evaluated.

\begin{abstract}
Outcome Measures: The outcome measures included BMD at the lumbar spine, femoral neck, and total proximal femur assessed at baseline and after a follow-up of 1 and 3 yr; semiquantitative visual assessment of vertebral fractures; and nonvertebral fractures based on written documentation.
\end{abstract}

Results: After 3 yr of strontium ranelate treatment, each percentage point increase in femoral neck and total proximal femur BMD was associated with a $3 \%$ (95\% adjusted confidence interval, 1-5\%) and $2 \%$
(1-4\%) reduction in risk of a new vertebral fracture, respectively. The 3 -yr changes in femoral neck and total proximal femur BMD explained $76 \%$ and $74 \%$, respectively, of the reduction in vertebral fractures observed during the treatment. Three-year changes in spine BMD were not statistically associated with the incidence of new vertebral fracture $(P=0.10)$. No significant associations were found between 3-yr changes in BMD and incidence of new nonvertebral fractures, but a trend was found for femoral neck $\operatorname{BMD}(P=0.09)$ and for total proximal femur $\operatorname{BMD}(P=0.07)$. An increase in femoral neck BMD after $1 \mathrm{yr}$ was significantly associated with the reduction in incidence of new vertebral fractures observed after 3 yr $(P=0.04)$.

Conclusion: During 3-yr strontium ranelate treatment, an increase in femoral neck BMD was associated with a proportional reduction in vertebral fracture incidence. (J Clin Endocrinol Metab 92: 3076-3081, 2007)
$\mathrm{O}$ STEOPOROSIS IS A disease characterized by a decrease in bone mass and deterioration in skeletal microarchitecture, leading to increased fragility and susceptibility to fracture. It is now widely accepted that one of the major determinants of skeletal weakness results from the bone loss that occurs after the menopause. Epidemiological studies of fracture incidence have shown that, in untreated patients, low bone mineral density (BMD) is consistently correlated with increased fracture risk (1-3).

Several randomized, controlled trials have demonstrated that pharmacological agents improve BMD and reduce the risk of fracture (4-10). However, the predictive value of BMD changes for fracture risk reduction is highly controversial for

First Published Online June 12, 2007

Abbreviations: BMD, Bone mineral density; DXA, dual energy x-ray absorptiometry; SOTI, Spinal Osteoporosis Therapeutic Intervention; TROPOS; TReatment Of Peripheral OSteoporosis.

JCEM is published monthly by The Endocrine Society (http://www. endo-society.org), the foremost professional society serving the endocrine community. antiresorptive agents $(11,12)$. Although increases in BMD resulting from various pharmacological treatments differ widely, reported reductions in vertebral fracture risk are rather similar (4-10). The relationship between changes in BMD and fracture risk may be different because these agents modify bone strength through different mechanisms of action at the tissue level (i.e. improvement in bone quality parameters) (13).

Strontium ranelate is composed of an organic moiety (ranelic acid) and two atoms of stable (nonradioactive) strontium. Although its molecular mechanism of action is not totally elucidated, strontium ranelate has been shown, in preclinical models, to reduce concomitantly bone resorption and increase bone formation $(14,15)$. Strontium ranelate was recently demonstrated to reduce significantly risk of vertebral (9), nonvertebral (10), and, in a high-risk population, hip fracture risk in women with postmenopausal osteoporosis. Moreover, significant increases in lumbar spine, femoral neck, and total hip BMD have been consistently reported in all populations exposed to strontium ranelate $(9,10,16,17)$. 
The relationship between measured, unadjusted BMD changes and fracture incidence during long-term treatment with strontium ranelate, however, is still unknown and is of clinical interest because strontium is a bone-seeking agent with a heavier atomic number than calcium, thus influencing BMD measurements $(18,19)$. Correlation between the increase in BMD and the reduction in fracture rates might also be of interest for monitoring strontium ranelate-treated patients in daily practice.

The objective of this study was to analyze the association between changes (1-yr and 3-yr) in BMD and vertebral and nonvertebral fracture risk during 3-yr treatment with strontium ranelate.

\section{Patients and Methods}

This post hoc analysis was performed on data from the SOTI (Spinal Osteoporosis Therapeutic Intervention) and the TROPOS (TReatment Of Peripheral OSteoporosis) studies $(9,10)$. The design and methodology of these two studies were fully described in previous reports $(9,10)$. Briefly, postmenopausal outpatients were recruited in 11 European countries and in Australia in two prospective, randomized, doubleblind, placebo-controlled trials, i.e. SOTI and TROPOS. Women were eligible for the SOTI study if they were at least $50 \mathrm{yr}$ old, had been postmenopausal for at least $5 \mathrm{yr}$, had at least one prevalent vertebral fracture confirmed by spinal radiography, and had a lumbar spine BMD of $0.840 \mathrm{~g} / \mathrm{cm}^{2}$ or less. In the TROPOS study, the criteria of eligibility were a femoral neck BMD of $0.600 \mathrm{~g} / \mathrm{cm}^{2}$ (corresponding with a T-score $<-2.5$ ), an age of 74 yr or older, or an age between 70 and 74 yr with at least one additional risk factor for fracture. These two studies lasted $5 \mathrm{yr}$, with the main statistical analysis over $3 \mathrm{yr}$, and compared $2 \mathrm{~g} / \mathrm{d}$ of strontium ranelate with placebo. Calcium and vitamin D supplementation was prescribed throughout the studies with the dosage determined during a run-in period. All participants gave written informed consent before enrollment, and the appropriate institutional review boards approved these two studies.

BMD was measured by dual energy x-ray absorptiometry (DXA) at baseline and at 6-month intervals at the lumbar spine (region of interest L2-L4) and proximal femur (Hologic Inc, Bedford, MA). All the scans were analyzed centrally, and the femoral neck, total proximal femur, and spine BMD T-scores were calculated according to the centralized European normative data (D.O. Slosman, Geneva, Switzerland). A quality control program including daily quality controls was conducted throughout the studies (20). Coefficients of variation for in vivo DXA measurements were $1.47 \%$ at the lumbar spine, $1.62 \%$ at the femoral neck, and $1.24 \%$ at the total proximal femur.

Vertebral fractures were assessed by the same team in a central facility throughout the 3-yr studies (C. Roux and J. Fetchenbaum, Paris, France), using a semiquantitative visual assessment of each vertebra, from T4 to L4 (21) (L5 vertebra was assessed as fractured or not fractured) (21). The semiquantitative grading scale was as follows: grade 0 , normal; grade 1 , a $20-25 \%$ decrease in the height of any vertebra; grade 2 , a $25-40 \%$ decrease; and grade 3 , a decrease of $40 \%$ or more. A new fracture was defined by a change in the score of a vertebra from grade 0 to grade 1 or more. A clinical vertebral fracture was defined as a new fracture (semiquantitative assessment) with either the presence of back pain or a body height loss of at least $1 \mathrm{~cm}$.

During the study, nonvertebral fractures were reported by study investigators based on written documentation provided and documented in the source document (radiograph, radiological report, copy of the hospitalization/emergency department report). Only documented nonvertebral fractures were taken into account in the statistical analysis. Fractures of the coccyx, skull, jaw, face, phalanx (fingers and toes), and ankle were not regarded as being related to osteoporosis and were not considered.

\section{Statistical analysis}

Patients were included in this particular analysis only if they had vertebral $\mathrm{x}$-rays and spine BMD performed at baseline and after $1 \mathrm{yr}$ and
$3 \mathrm{yr}$, independent of drug compliance. A total of 3640 patients (1813 from the strontium ranelate group and 1827 from the placebo group) met these inclusion criteria. Out of these 3640 patients, 1100 were in the SOTI trial and 2540 in the TROPOS trial. The association between changes in BMD and fracture incidence (vertebral and nonvertebral) was assessed only in the strontium ranelate-treated patients through a logistic regression analysis with age, body mass index, number of prevalent vertebral fractures, and baseline BMD as covariates. The Mann-Whitney test was used to compare the changes in BMD after strontium ranelate treatment in patients with and without new fractures. We also assessed the risk of sustaining at least one new fracture in different groups stratified for different BMD changes (i.e. $\leq$ or $>3 \%$ of BMD change), after controlling for covariates. We also performed the analysis with the absolute changes in BMD, using the individual smallest detectable difference as a reference (22). The proportion of treatment effect explained by BMD changes was assessed from logistic regression models that included, besides the effects for treatment and end points, fixed effects for age, body mass index, BMD, and number of prevalent vertebral osteoporotic fractures at the start of follow-up. The proportion was computed as the ratio of the risk reduction explained by the surrogate alone over the overall risk reduction by treatment and surrogate (23).

\section{Results}

Baseline characteristics of this study population are presented in Table 1. In patients treated with strontium ranelate, a 3-yr increase in femoral neck and total proximal femur BMD was statistically associated with a reduction in the incidence of new vertebral fractures $(P=0.001$ and $P=0.008$, respectively). Changes in spine BMD were not statistically associated with the incidence of vertebral fracture $(P=0.10)$. For each percentage point increase in femoral neck or total proximal femur BMD observed after $3 \mathrm{yr}$, the risk of sustaining a new vertebral fracture after 3 yr decreased by $3 \%$ [95\% adjusted confidence interval (CI), 1-5\%] and 2\% (1$4 \%)$, respectively. Figure 1 shows the relationship between vertebral fracture rate and total proximal femur BMD changes in the placebo and strontium ranelate groups. The results did not substantially change when clinical vertebral fractures were considered, i.e. $5 \%(2-7 \%)$ and $4 \%(2-6 \%)$ decreases in risk were observed for each percentage point increase after $3 \mathrm{yr}$ in femoral neck and total proximal femur $\mathrm{BMD}$, respectively.

Using the method developed by Li et al. (23), the changes in total proximal femur and femoral neck BMD explained $74 \%$ and $76 \%$, respectively, of the vertebral antifracture efficacy of strontium ranelate.

On average, patients sustaining new vertebral fractures over 3 yr gain less femoral neck BMD (mean [sD]) $(+4.5 \%$ [9.1]) than patients without vertebral fractures $(+5.7 \%$ [7.4]

TABLE 1. Baseline characteristics of the strontium ranelate group included in this study $(\mathrm{n}=1813)$

\begin{tabular}{lccl}
\hline \multicolumn{1}{c}{ Variables } & Mean & Median & \multicolumn{1}{c}{ SD } \\
\hline Age (yr) & 73.3 & 73.0 & 6.0 \\
Body mass index $\left(\mathrm{kg} / \mathrm{m}^{2}\right)$ & 25.9 & 25.6 & 4.0 \\
BMD $\left(\mathrm{g} / \mathrm{cm}^{2}\right)$ & & & \\
$\quad$ Lumbar spine & 0.774 & 0.764 & 0.147 \\
$\quad$ Total hip & 0.674 & 0.674 & 0.095 \\
$\quad$ Femoral neck & 0.574 & 0.574 & 0.072 \\
BMD (T-score) & & & \\
$\quad$ Lumbar spine & -3.06 & -3.17 & 1.53 \\
$\quad$ Total hip & -2.48 & -2.48 & 0.94 \\
$\quad$ Femoral neck & -2.96 & -2.94 & 0.63 \\
No. of previous vertebral fractures & 1.19 & 0 & 1.92 \\
\hline
\end{tabular}


FIG. 1. Logistic regression analysis curves $(95 \%$ CI $)$ of the percentage changes in femoral neck BMD at $3 \mathrm{yr}$ and the new vertebral fractures rates at $3 \mathrm{yr}$ in the placebo and strontium ranelate groups.

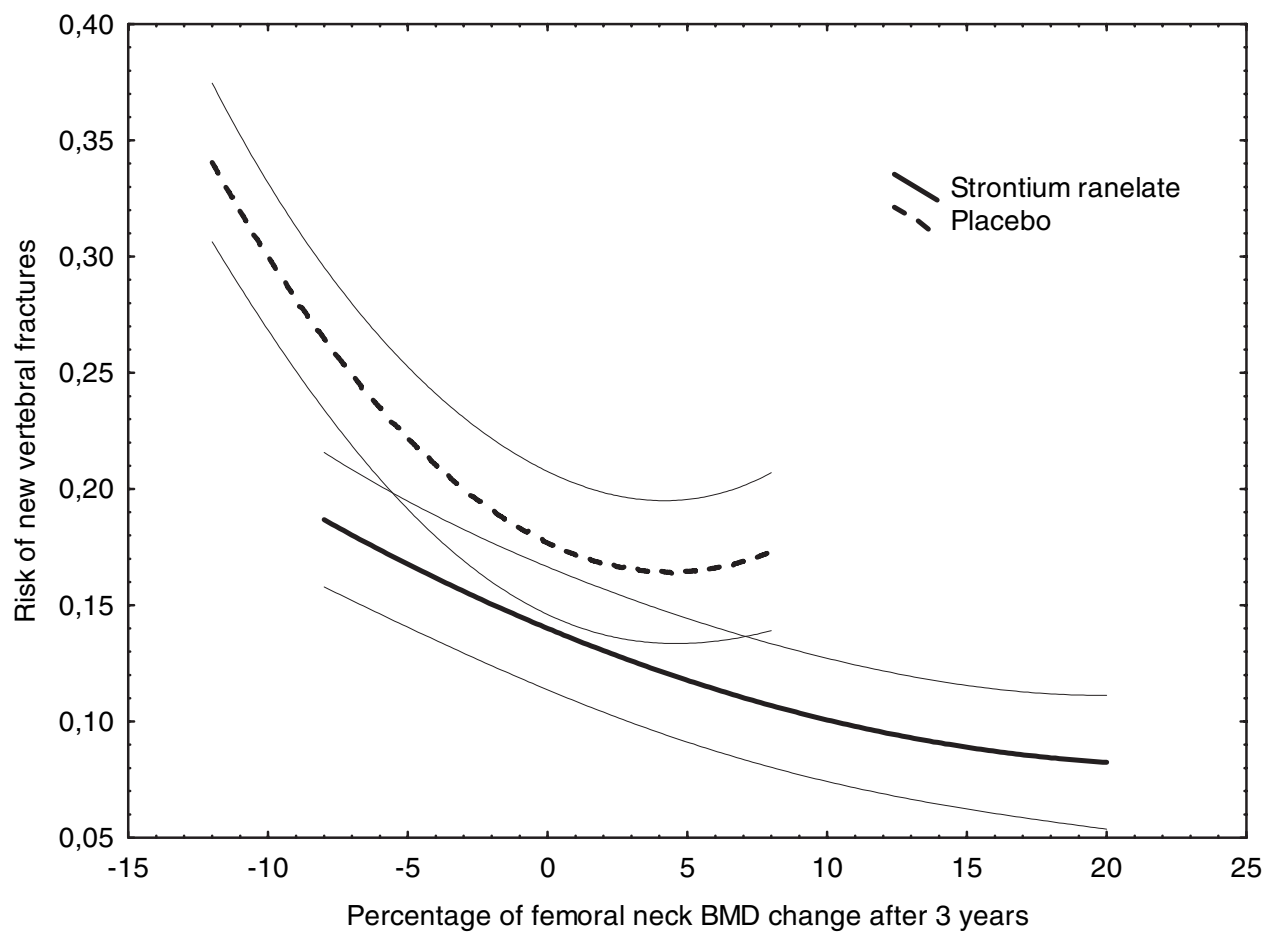

( $P=0.03$ between the two groups). When considering clinical vertebral fractures, patients with new fractures experienced less gain in femoral neck BMD $(+3.6 \%$ [9.4]) than patients without fractures $(5.7 \%$ [7.5]) $(P=0.009$ between the two groups).

Strontium ranelate-treated patients experiencing an increase in femoral neck or total proximal femur BMD $(>0 \%)$ after 3-yr treatment have a lower vertebral fracture incidence, compared with similarly treated patients who lose BMD (Table 2). After controlling for covariates, patients with an improvement of at least 3\% in femoral neck BMD were at a lower risk of sustaining new vertebral fractures (odds ratio $0.62[0.42-0.81])$ than patients without such improvement. The results were in the same range when considering changes in total proximal femur BMD (odds ratio 0.63 [0.490.86]). The risk of sustaining new clinical vertebral fractures in patients in the highest quartile of femoral neck BMD change $(>9.49 \%)$ was reduced by $41 \%(P<0.02)$ compared with patients in the lowest quartiles $(<1.01 \%)$.

Of the patients treated with strontium ranelate, $45.7 \%$ experienced an absolute gain of $0.033 \mathrm{~g} / \mathrm{cm}^{2}$ in femoral neck BMD after 3-yr treatment, corresponding with the smallest detectable difference in femoral neck BMD measurement. The risk of a new vertebral fracture in these patients was reduced by $24 \%(2-41 \%)(P=0.03)$, compared with patients without such gain in BMD. Similarly, $58.2 \%$ of the patients experienced an increase in total proximal femur BMD, the smallest detectable difference of $0.038 \mathrm{~g} / \mathrm{cm}^{2}$. The risk of a new vertebral fracture in these patients was reduced by $34 \%$ $(15-48 \%)(P<0.001)$, compared with patients without this BMD increase.

No significant associations were found between 3-yr change in spine BMD and incidence of new nonvertebral fractures $(P=0.21)$, but a trend was found for femoral neck $\operatorname{BMD}(P=0.09)$ and for total proximal femur $\operatorname{BMD}(P=0.07)$.

When considering the changes in BMD observed after $1 \mathrm{yr}$ of strontium ranelate, the logistic regression analysis including age, body mass index, prevalence of vertebral fractures, and baseline BMD as covariates showed that 1-yr increases in femoral neck BMD were associated with the reduction in incidence of new vertebral fractures observed over 3 yr $(P=$ 0.04). However, 1-yr increases in total proximal femur and lumbar BMD were not significantly associated with the reduction in vertebral fractures $(P=0.06$ and $P=0.18$, respectively). For each percentage point increase in femoral neck BMD after $1 \mathrm{yr}$, the incidence of a new clinical vertebral fracture after $3 \mathrm{yr}$ decreased by 3\% (95\% CI, 1-6\%). The reduction was of similar magnitude $[3 \%(95 \% \mathrm{CI}, 1-5 \%) ; P=$ 0.04] for clinical vertebral fractures. Patients experiencing an increase in femoral neck BMD $(>0 \%)$ after 1 yr had a $21 \%$ reduction $(95 \% \mathrm{CI}, 1-37 \%)(P=0.04)$ in the risk of a new

TABLE 2. Incidence of new vertebral fractures stratified for patients with and without 3-yr increases in femoral neck or total proximal femur BMD

\begin{tabular}{|c|c|c|c|c|c|c|c|c|}
\hline & \multicolumn{4}{|c|}{ Femoral neck BMD changes at $3 \mathrm{yr}$} & \multicolumn{4}{|c|}{ Total proximal femur BMD changes at $3 \mathrm{yr}$} \\
\hline & $\begin{array}{c}\leq 0 \\
(\mathrm{n}=366)\end{array}$ & $\begin{array}{c}>0 \\
(\mathrm{n}=1420)\end{array}$ & $P$ & $\begin{array}{l}\text { Relative risk } \\
(95 \% \mathrm{CI})\end{array}$ & $\begin{array}{c}\leq 0 \\
(\mathrm{n}=258)\end{array}$ & $\begin{array}{c}>0 \\
(\mathrm{n}=1528)\end{array}$ & $P$ & $\begin{array}{l}\text { Relative risk } \\
(95 \% \mathrm{CI})\end{array}$ \\
\hline Vertebral fractures & $17.2 \%$ & $11.4 \%$ & 0.003 & $0.66(0.51-0.87)$ & $21.7 \%$ & $11.1 \%$ & $<0.0001$ & $0.51(0.39-0.67)$ \\
\hline Clinical vertebral fractures & $10.9 \%$ & $6.1 \%$ & 0.001 & $0.56(0.39-0.80)$ & $14.6 \%$ & $5.8 \%$ & $<0.0001$ & $0.40(0.28-0.57)$ \\
\hline
\end{tabular}


vertebral fracture over $3 \mathrm{yr}$, compared with patients without increase in BMD.

In strontium ranelate-treated patients, no significant associations were found between the 1-yr change in BMD and the incidence of new nonvertebral fractures $(P=0.63$ for spine BMD, $P=0.18$ for femoral neck BMD, and 0.41 for total proximal femur BMD).

\section{Discussion}

We have demonstrated an association between vertebral fracture incidence and changes in total proximal femur BMD, as well as femoral neck BMD, in patients treated with strontium ranelate for $3 \mathrm{yr}$. Applying the methodology recently used for antiresorptive agents $(11,24)$, we calculated that, during 3-yr treatment with strontium ranelate, the change in total proximal femur BMD or femoral neck BMD explained more than $70 \%$ of the vertebral fracture risk reduction .

These observations of an association between BMD changes and fracture risk are supported by preclinical studies. Indeed, there is a robust correlation between the increase in BMD during strontium ranelate treatment and improvement in biomechanical properties of the vertebral and upper femoral extremity in intact female rats (15).

We found no association between lumbar BMD changes and vertebral fracture incidence during the 3-yr treatment. Theoretically, based on greater spine BMD changes observed after 3-yr treatment and better lumbar spine precision error (compared with femoral neck), it should be easier to show associations between BMD and vertebral fracture using spinal BMD measurements than using femoral neck. Indeed, some studies have found a significant association between spine BMD changes and vertebral fracture incidence $(25,26)$. However, with age, the presence or worsening of degenerative conditions of the spine, such as osteophytes and endplate sclerosis, contribute to the variation in lumbar spine BMD measurement (27). Moreover, microarchitectural deformities in the vertebra may accumulate over time and contribute to the apparent increase in the lumbar spine BMD and ultimately lead to fracture $(28,29)$.

Studies exploring the association between BMD changes and fracture reduction have been mainly conducted with antiresorptive agents (30-32), but have yielded contradictory results (12,33-36). Among women taking alendronate, Hochberg et al. (25) found that larger increases in total hip and spine BMD were associated with a lower risk of new vertebral fractures. However, another study using a meta-analytic approach showed that the percentage reduction in vertebral fracture risk attributable to increase in spine BMD after alendronate treatment was only 16\% (33). Moreover, it has recently been shown that women losing BMD at the lumbar spine $(0-4 \%)$ while on alendronate still had a reduction in vertebral fracture risk compared with their counterparts in the placebo group (37). With raloxifene, increases in femoral neck BMD after treatment account for only $4 \%$ of the effect on vertebral fracture risk (34). More recently, increases in lumbar spine and femoral neck BMD have been shown to account for only $18 \%$ and $11 \%$, respectively, of the effect of risedronate on vertebral fracture incidence (24). However, risedronate-treated patients whose BMD decreased were at significantly greater risk of sustaining a vertebral fracture than patients whose BMD increased. Meta-analytic approaches pooling different antiresorptive agents also produced conflicting results. Trials that reported larger increases in BMD tended to observe greater reductions in vertebral fracture risk (26). Using a Poisson regression, the model predicts that treatments that increase spine BMD by $8 \%$ would reduce risk of fracture by $54 \%$ and that most of the total effect of treatment is explained by the increase in BMD (26). Another meta-analysis has shown that the risk of nonvertebral fractures decreased in patients with an increase in BMD during treatment with antiresorptive agents (35). Reanalysis of these data, however, using the same statistical methods but correcting for discrepancies in the reported BMD and person-year data, suggested that the magnitude of the fracture risk reduction was not associated with the increase in BMD (36). Thus, there is limited evidence to justify use of the BMD increase during antiresorptive therapy as a reliable indicator of fracture risk reduction $(11,12)$. Very few studies have assessed the association between BMD changes and fracture reduction with bone-forming agents. To the best of our knowledge, the only study dealing with this topic found that an approximate $9-14 \%$ increase in spine BMD after a treatment with teriparatide (i.e. $0.09 \mathrm{~g} / \mathrm{cm}^{2}$ in women with starting BMD 0.64-1.01) was associated with $30-41 \%$ fracture risk reductions (38). This calculates to $3 \%$ risk reduction for every $1 \%$ increase in spinal BMD.

Because strontium is a heavier element than calcium, its incorporation into bone influences BMD measurements (18, $19,39)$. The combined effects of strontium distribution in bone and increased x-ray absorption of strontium compared with calcium leads to an amplification of BMD measurement by DXA. These effects of strontium account for approximately $50 \%$ of the measured changes in BMD (10). However, an algorithm for adjustment of BMD involves a number of assumptions and cannot be used for individual patients (19). In the present study, the association between BMD changes and fracture incidence during 3-yr treatment with strontium ranelate was obtained with unadjusted BMD values for strontium because in daily practice the clinician will deal with unadjusted BMD assessment.

Our study also showed that 1-yr changes in femoral neck BMD were associated with future (3-yr) vertebral fracture rates in patients treated with strontium. For each percentage point increase in femoral neck BMD after $1 \mathrm{yr}$, the risk of sustaining a new clinical vertebral fracture after 3 yr decreased by $3 \%$. However, it should be acknowledged that the $95 \%$ CI (28) is quite wide. Anyway, these results are important for monitoring strontium ranelate treatment because it is then possible, after only 1 yr of treatment, to identify those patients who will have the lowest risk of new vertebral fractures over 3-yr treatment. Feedback of such results to the patients could help increase treatment compliance, as recently demonstrated (40). However, the exact impact of monitoring BMD on compliance needs to be assessed.

It should also be pointed out that some patients experienced a decrease in BMD at $1 \mathrm{yr}$, but an increase in BMD at 3 yr. This reflects the principle of "regression to the mean" (41). In our study population, $9.7 \%$ of the women experienced a loss of spine BMD after $1 \mathrm{yr}$, but an increase after 3 
yr. The same has been shown for femoral neck and total proximal femur BMD (19.8 and $14.8 \%$ of patients, respectively). These results confirm the data of Cummings et al. (41), who showed that most women who lose BMD during the first year of treatment with alendronate or raloxifene would gain BMD if the same treatment were continued for a second year. However, the value of changing or adding treatments in women who persistently lose BMD has not been studied.

As previously discussed, the BMD changes accounted for a substantial part of the vertebral antifracture efficacy of strontium ranelate. However, BMD changes (in the spine but also in the total proximal femur and femoral neck) do not wholly explain the vertebral fracture efficacy of strontium ranelate. The relationship between BMD changes and fracture risk is confounded by other factors that contribute to the etiology of vertebral fracture. One of these factors is the change in bone microarchitecture during treatment with strontium ranelate, which has been observed in rats (42). As shown by animal studies, these positive effects on bone quality are also essential for antifracture efficacy (43). In threedimensional studies of bone microarchitecture in animals, bone architecture contributes to vertebral strength over and beyond the contributions of bone quantity (44). Even if they are not exhaustively defined in the literature (36), these findings could also account for the reduction in vertebral fracture risk seen with strontium ranelate.

In our study, we failed to find statistically significant associations between 3-yr changes in BMD and the incidence of new nonvertebral fractures, although a trend was found for femoral neck BMD and for total proximal femur BMD. In strontium ranelate-treated patients, the association between changes in BMD and fracture risk reduction seems to be stronger for vertebral fractures than for nonvertebral fractures. It could be hypothesized that other factors, such as falls, have a substantial influence on this relationship.

Despite their homogeneity, some of these findings should be viewed cautiously. For each percentage point increase in femoral neck BMD, the relative risk of new vertebral fracture decreases by $3 \%$. However, despite the large number of participants in this trial, the $95 \%$ CI for this estimate is relatively wide (between 1 and 5\%). Our analysis was based on measurement of BMD by DXA. It should be acknowledged that imprecision in BMD measurement could modify the association between BMD changes and fracture risk reduction. In this particular study, BMD was assessed with strict quality control (20).

In conclusion, the increase in BMD observed after 1 (femoral neck) and 3 yr (femoral neck and total proximal femur) was associated with a reduction in vertebral fracture incidence during 3-yr treatment with strontium ranelate. This relationship is of clinical relevance and may be of interest in the monitoring of patients treated with strontium ranelate.

\section{Acknowledgments}

Received December 13, 2006. Accepted May 31, 2007

Address all correspondence and requests for reprints to: Olivier Bruyere, Ph.D., Department of Public Health, Epidemiology and Health Economics, University of Liège, CHU Sart-Tilman, Bât B23, B-4000 Liège, Belgium. E-mail: olivier.bruyere@ulg.ac.be.

This work was supported by Servier.
Disclosure Summary: C.R., T.D.S., K.B., J.-M.K., and J.-Y.R. have received lecture fees from Servier. O.B., T.D.S., K.B., and J.-Y.R. consult for Servier. J.D., D.O.S., P.F., J.-P.D., M.D.-C., C.A., and S.P.-N. have nothing to disclose.

\section{References}

1. Cummings SR, Black DM, Nevitt MC, Browner W, Cauley J, Ensrud K, Genant HK, Palermo L, Scott J, Vogt TM 1993 Bone density at various sites for prediction of hip fractures. The Study of Osteoporotic Fractures Research Group. Lancet 341:72-75

2. Melton 3rd LJ, Atkinson EJ, O'Fallon WM, Wahner HW, Riggs BL 1993 Long-term fracture prediction by bone mineral assessed at different skeletal sites. J Bone Miner Res 8:1227-1233

3. Marshall D, Johnell O, Wedel H 1996 Meta-analysis of how well measures of bone mineral density predict occurrence of osteoporotic fractures. BMJ 312: 1254-1259

4. Black DM, Cummings SR, Karpf DB, Cauley JA, Thompson DE, Nevitt MC, Bauer DC, Genant HK, Haskell WL, Marcus R, Ott SM, Torner JC, Quandt SA, Reiss TF, Ensrud KE 1996 Randomised trial of effect of alendronate on risk of fracture in women with existing vertebral fractures. Fracture Intervention Trial Research Group. Lancet 348:1535-1541

5. Reginster J, Minne HW, Sorensen OH, Hooper M, Roux C, Brandi ML, Lund B, Ethgen D, Pack S, Roumagnac I, Eastell R 2000 Randomized trial of the effects of risedronate on vertebral fractures in women with established postmenopausal osteoporosis. Vertebral Efficacy with Risedronate Therapy (VERT) Study Group. Osteoporos Int 11:83-91

6. Ettinger B, Black DM, Mitlak BH, Knickerbocker RK, Nickelsen T, Genant HK, Christiansen C, Delmas PD, Zanchetta JR, Stakkestad J, Gluer CC, Krueger K, Cohen FJ, Eckert S, Ensrud KE, Avioli LV, Lips P, Cummings SR 1999 Reduction of vertebral fracture risk in postmenopausal women with osteoporosis treated with raloxifene: results from a 3-year randomized clinical trial. Multiple Outcomes of Raloxifene Evaluation (MORE) Investigators. JAMA 282:637-645

7. Neer RM, Arnaud CD, Zanchetta JR, Prince R, Gaich GA, Reginster JY, Hodsman AB, Eriksen EF, Ish-Shalom S, Genant HK, Wang O, Mitlak BH 2001 Effect of parathyroid hormone (1-34) on fractures and bone mineral density in postmenopausal women with osteoporosis. N Engl J Med 344:14341441

8. Harris ST, Watts NB, Genant HK, McKeever CD, Hangartner T, Keller M, Chesnut 3rd CH, Brown J, Eriksen EF, Hoseyni MS, Axelrod DW, Miller PD 1999 Effects of risedronate treatment on vertebral and nonvertebral fractures in women with postmenopausal osteoporosis: a randomized controlled trial. Vertebral Efficacy with Risedronate Therapy (VERT) Study Group. JAMA 282:1344-1352

9. Meunier PJ, Roux C, Seeman E, Ortolani S, Badurski JE, Spector TD, Cannata J, Balogh A, Lemmel EM, Pors-Nielsen S, Rizzoli R, Genant HK, Reginster JY 2004 The effects of strontium ranelate on the risk of vertebral fracture in women with postmenopausal osteoporosis. N Engl J Med 350:459-468

10. Reginster JY, Seeman E, De Vernejoul MC, Adami S, Compston J, Phenekos C, Devogelaer JP, Curiel MD, Sawicki A, Goemaere S, Sorensen OH, Felsenberg D, Meunier PJ 2005 Strontium ranelate reduces the risk of nonvertebral fractures in postmenopausal women with osteoporosis: Treatment of Peripheral Osteoporosis (TROPOS) study. J Clin Endocrinol Metab 90:2816-2822

11. Li Z, Chines AA, Meredith MP 2004 Statistical validation of surrogate endpoints: is bone density a valid surrogate for fracture? J Musculoskelet Neuronal Interact 4:64-74

12. Delmas PD, Li Z, Cooper C 2004 Relationship between changes in bone mineral density and fracture risk reduction with antiresorptive drugs: some issues with meta-analyses. J Bone Miner Res 19:330-337

13. Eastell R 1998 Treatment of postmenopausal osteoporosis. N Engl J Med 338:736-746

14. Marie PJ, Ammann P, Boivin G, Rey C 2001 Mechanisms of action and therapeutic potential of strontium in bone. Calcif Tissue Int 69:121-129

15. Ammann P, Shen V, Robin B, Mauras Y, Bonjour JP, Rizzoli R 2004 Strontium ranelate improves bone resistance by increasing bone mass and improving architecture in intact female rats. J Bone Miner Res 19:2012-2020

16. Meunier PJ, Slosman DO, Delmas PD, Sebert JL, Brandi ML, Albanese C, Lorenc R, Pors-Nielsen S, De Vernejoul MC, Roces A, Reginster JY 2002 Strontium ranelate: dose-dependent effects in established postmenopausal vertebral osteoporosis-a 2-year randomized placebo controlled trial. J Clin Endocrinol Metab 87:2060-2066

17. Reginster JY, Meunier PJ 2003 Strontium ranelate phase 2 dose-ranging studies: PREVOS and STRATOS studies. Osteoporos Int 14 Suppl 3:S56-S65

18. Blake GM, Fogelman I 2005 Long-term effect of strontium ranelate treatment on BMD. J Bone Miner Res 20:1901-1904

19. Nielsen SP, Slosman D, Sorensen OH, Basse-Cathalinat B, De Cassin P, Roux CR, Meunier PJ 1999 Influence of strontium on bone mineral density and bone mineral content measurements by dual x-ray absorptiometry. J Clin Densitom 2:371-379

20. Slosman D, Provvedini DM, Meunier PJ, Delmas PD, Sebert JL, De Ver- 
nejoul MC, Tsouderos Y, Reginster J 1999 The use of different dual x-ray absorptiometry brands in a multicenter clinical trial. J Clin Densitom 2:37-44

21. Genant HK, Wu CY, van Kuijk C, Nevitt MC 1993 Vertebral fracture assessment using a semiquantitative technique. J Bone Miner Res 8:1137-1148

22. Ravaud P, Reny JL, Giraudeau B, Porcher R, Dougados M, Roux C 1999 Individual smallest detectable difference in bone mineral density measurements. J Bone Miner Res 14:1449-1456

23. Li Z, Meredith MP, Hoseyni MS 2001 A method to assess the proportion of treatment effect explained by a surrogate endpoint. Stat Med 20:3175-3188

24. Watts NB, Cooper C, Lindsay R, Eastell R, Manhart MD, Barton IP, van Staa TP, Adachi JD 2004 Relationship between changes in bone mineral density and vertebral fracture risk associated with risedronate: greater increases in bone mineral density do not relate to greater decreases in fracture risk. J Clin Densitom 7:255-261

25. Hochberg MC, Ross PD, Black D, Cummings SR, Genant HK, Nevitt MC, Barrett-Connor E, Musliner T, Thompson D 1999 Larger increases in bone mineral density during alendronate therapy are associated with a lower risk of new vertebral fractures in women with postmenopausal osteoporosis. Fracture Intervention Trial Research Group. Arthritis Rheum 42:1246-1254

26. Wasnich RD, Miller PD 2000 Antifracture efficacy of antiresorptive agents are related to changes in bone density. J Clin Endocrinol Metab 85:231-236

27. Liu G, Peacock M, Eilam O, Dorulla G, Braunstein E, Johnston CC 1997 Effect of osteoarthritis in the lumbar spine and hip on bone mineral density and diagnosis of osteoporosis in elderly men and women. Osteoporos Int 7:564-569

28. Kleerekoper M, Villanueva AR, Stanciu J, Rao DS, Parfitt AM 1985 The role of three-dimensional trabecular microstructure in the pathogenesis of vertebral compression fractures. Calcif Tissue Int 37:594-597

29. Legrand E, Chappard D, Pascaretti C, Duquenne M, Krebs S, Rohmer V Basle MF, Audran M 2000 Trabecular bone microarchitecture, bone minera density, and vertebral fractures in male osteoporosis. J Bone Miner Res 15: 13-19

30. Bonnick SL, Shulman L 2006 Monitoring osteoporosis therapy: bone mineral density, bone turnover markers, or both? Am J Med 119:S25-S31

31. Miller PD 2005 Bone density and markers of bone turnover in predicting fracture risk and how changes in these measures predict fracture risk reduction. Curr Osteoporos Rep 3:103-110

32. Miller PD 2007 Monitoring osteoporosis therapies. Curr Osteoporos Rep 5:38-43

33. Cummings SR, Karpf DB, Harris F, Genant HK, Ensrud K, LaCroix AZ, Black
DM 2002 Improvement in spine bone density and reduction in risk of vertebral fractures during treatment with antiresorptive drugs. Am J Med 112:281-289

34. Sarkar S, Mitlak BH, Wong M, Stock JL, Black DM, Harper KD 2002 Relationships between bone mineral density and incident vertebral fracture risk with raloxifene therapy. J Bone Miner Res 17:1-10

35. Hochberg MC, Greenspan S, Wasnich RD, Miller P, Thompson DE, Ross PD 2002 Changes in bone density and turnover explain the reductions in incidence of nonvertebral fractures that occur during treatment with antiresorptive agents. J Clin Endocrinol Metab 87:1586-1592

36. Delmas PD, Seeman E 2004 Changes in bone mineral density explain little of the reduction in vertebral or nonvertebral fracture risk with anti-resorptive therapy. Bone 34:599-604

37. Chapurlat RD, Palermo L, Ramsay P, Cummings SR 2005 Risk of fracture among women who lose bone density during treatment with alendronate. The Fracture Intervention Trial. Osteoporos Int 16:842-848

38. Chen P, Miller PD, Delmas PD, Misurski DA, Krege JH 2006 Change in lumbar spine BMD and vertebral fracture risk reduction in teriparatide-treated postmenopausal women with osteoporosis. J Bone Miner Res 21:1785-1790

39. El-Hajj Fuleihan G 2004 Strontium ranelate-a novel therapy for osteoporosis or a permutation of the same? N Engl J Med 350:504-506

40. Solomon DH, Avorn J, Katz JN, Finkelstein JS, Arnold M, Polinski JM, Brookhart MA 2005 Compliance with osteoporosis medications. Arch Intern Med 165:2414-2419

41. Cummings SR, Palermo L, Browner W, Marcus R, Wallace R, Pearson J, Blackwell T, Eckert S, Black D 2000 Monitoring osteoporosis therapy with bone densitometry: misleading changes and regression to the mean. Fracture Intervention Trial Research Group. JAMA 283:1318-1321

42. Grynpas MD, Hamilton E, Cheung R, Tsouderos Y, Deloffre P, Hott M, Marie PJ 1996 Strontium increases vertebral bone volume in rats at a low dose that does not induce detectable mineralization defect. Bone 18:253-259

43. Boonen S, Haentjens P, Vandenput L, Vanderschueren D 2004 Preventing osteoporotic fractures with antiresorptive therapy: implications of microarchitectural changes. J Intern Med 255:1-12

44. Borah B, Dufresne TE, Cockman MD, Gross GJ, Sod EW, Myers WR, Combs KS, Higgins RE, Pierce SA, Stevens ML 2000 Evaluation of changes in trabecular bone architecture and mechanical properties of minipig vertebrae by three-dimensional magnetic resonance microimaging and finite element modeling. J Bone Miner Res 15:1786-1797

JCEM is published monthly by The Endocrine Society (http://www.endo-society.org), the foremost professional society serving the endocrine community. 